Short communication

\title{
Response of selenium-dependent glutathione peroxidase in the freshwater bivalve Anodonta woodiana exposed to 2,4- dichlorophenol,2,4,6-trichlorophenol and pentachlorophenol
}

\author{
Xichao Xia ${ }^{\text {a, b, * }}$, Chunxiu Hua ${ }^{a}$, Shipeng Xue ${ }^{a}$, Bingqin Shi ${ }^{\text {, }}$ Gaixia Gui ${ }^{\text {, }}$ \\ Dongxian Zhang a, Xiying Wang ${ }^{\mathrm{a}}$, Lianghong Guo ${ }^{\mathrm{b},{ }^{* *}}$ \\ ${ }^{a}$ Basal Medicine Institution of Nanyang Medical College, Nanyang 473041, Henan Province, China \\ b State Key Laboratory of Environmental Chemistry and Eco-toxicology, Research Centre for Eco-environmental Sciences, Chinese Academy of Sciences, \\ Beijing 100085, China
}

\section{A R T I C L E I N F O}

\section{Article history:}

Received 10 March 2016

Received in revised form 8 June 2016

Accepted 8 June 2016

Available online 9 June 2016

\section{Keywords:}

Anodonta woodiana

AwSeGPx

2,4-Dichlorophenol

2,4,6-Trichlorophenol

Pentachlorophenol

\begin{abstract}
A B S T R A C T
2,4-dichlorophenol (2,4-DCP), 2,4,6-trichlorophenol (2,4,6-TCP), and pentachlorophenol (PCP) pose a health risk to aquatic organism and humans, and are recognized as persistent priority pollutants. Selenium dependent glutathione peroxidase (Se-GPx) belongs to the family of selenoprotein, which acts mainly as an antioxidant role in the cellular defense system. In the current study, a Se-GPx full length cDNA was cloned from Anodonta woodiana and named as AwSeGPx. It had a characteristic codon at 165TGA167 that corresponds to selenocysteine( $\mathrm{Sec}$ ) amino acid as U44. The full length cDNA consists of $870 \mathrm{bp}$, an open reading frame (ORF) of 585 bp encoded a polypeptide of 195 amino in which conserved domain (68LGFPCNQF75) and a glutathione peroxide-1 GPX active site (32GKVILVENVASLUGTT47) were observed. Additionally, the eukaryotic selenocysteine insertion sequence (SECIS) was conserved in the 3'UTR. The AwSeGPx amino acid sequence exhibited a high similarity with that of other Se-GPx. Realtime PCR analysis revealed that AwSeGPx mRNA had a widely distribution, but the highest level was observed in hepatopancreas. AwSeGPx mRNA expression was significantly up-regulated in hepatopancreas, gill and hemocytes after 2,4-DCP, 2,4,6-TCP and PCP exposure. Under similar environment, clams A. woodiana showed a more sensitive to PCP than that of 2,4-DCP and 2,4,6-TCP. These results indicate that AwSeGPx plays a protective role in eliminating oxidative stress derived from 2,4-DCP, 2,4,6-TCP and PCP treatment.
\end{abstract}

๑) 2016 Elsevier Ltd. All rights reserved.

\section{Introduction}

Products chlorophenols (CPs) are ubiquitous globally in surface waters, groundwater, wastewater, sludge and drinking waters because they are widely used in agriculture and industry as pesticides, wood preservatives, and personal care formulations [1,2]. Furthermore, CPs are the most direct precursors of dioxin and polyaromatic compounds in incinerator gas emissions [3]. CPs have received worldwide concern due to their toxicity to aquatic life, persistence, and potential to bioaccumulation [4,5]. Among CPs,

\footnotetext{
* Corresponding author. Basal Medicine Institution of Nanyang Medical College, Nanyang 473041, Henan Province, China.

** Corresponding author.

E-mail addresses: xiaxichao8336@163.com (X. Xia), lhguo@rcees.ac.cn (L. Guo).
}

2,4-dichlorophenol (2,4-DCP),2,4,6-trichlorophenol (2,4,6-TCP), and pentachlorophenol(PCP) are ubiquitous in significant quantities, which pose a health risk to aquatic organism and humans and are recognized as persistent priority pollutants in the United States, Europe and China [6,7]. At present, 2,4-DCP, 2,4,6-TCP and PCP exist widely in over 600 sites in the 7 major watersheds and 3 drainage areas of China [8]. They have been shown to induce reproductive toxicity, endocrine activity and oxidative stress in aquatic organism [9]. Previous studies indicate that principal mechanisms of action of PCP-induced toxicity are related to the uncoupling of oxidative phosphorylation in mitochondria and the generation of reactive oxygen species (ROS) [9,10].

In healthy organism, total ROS level stay a relatively low level and ROS will be rapidly eliminated by an array of anti-oxidant enzymes to maintain a balance between ROS level and anti-oxidant enzyme activity [11,12]. Moderate oxidative stress in a shorter 
time may function as an important player to induce different antioxidant enzyme expressions to deal with different ROS [13,14]. However, higher ROS concentrations exceed the scavenging capacity of anti-oxidant enzymes could bring about the risk of DNA damage, lipid peroxidation and protein carbonylation $[15,16]$. Orchestra of anti-oxidant enzymes is a key hallmark of organism homeostasis. Among of these enzymes, glutathione peroxidases (GPx) are one major component of the antioxidant system, which catalyze the reduction of hydrogen peroxide, two isoforms had been identified: selenium-dependent GPx (Se-GPx) and selenium independent GPx. SeGPx catalyzes the reduction of organic and inorganic peroxides like hydrogen peroxide $\left(\mathrm{H}_{2} \mathrm{O}_{2}\right)$ while seleniumindependent GPx reduces only organic peroxide [17].

Now, highlight of Se-GPx enzyme protecting organisms from oxidative damage gained widely attention. In mammals, four major members of Se-GPx (GPx-1 to GPx-4) have been identified, and show specificities for the hydroperoxide substrates. GPX-1 and GPX-2 reduce rapidly hydrogenperoxide or fatty acid hydroperoxides, GPX-4 can react with phospholipid hydroperoxides $[18,19]$. It has demonstrated that enhancement of Se-GPX activities contribute to attenuate oxidative injury in mammals and some fish species [20]. In mussel Mytilus galloprovincialis, inhibition of SeGPX activity by Hg could promote a shift in the balance between oxidants and antioxidants in favor of oxidants, resulted in the enhancement of $\mathrm{Hg}$ induced oxidative and genotoxic effects [21]. In Venerupis philippinarum, administration of heavy metals, such as $\mathrm{Cd}$ and $\mathrm{Cu}$, can results in a significant induction of VpSe-GPx expression [22].

Freshwater clams, Anodonta woodiana are widely distributed in the world and functions as a main criteria required for a bioindicator organism. Earlier studies have revealed the ability of A. woodiana to accumulate trace elements and pesticides, as well as its potential to detect genotoxicity [23]. In addition, these mussels have important ecosystem functions such as particle filtration and processing, nutrient release, and sediment mixing [23,24]. Considering here, their decline of population can profoundly affect aquatic ecosystem. Take into consideration of great interest to investigate the effect of 2,4-DCP, 2,4,6-TCP and PCP on A. Woodiana, in the current study, one complete sequence of Se-GPx has been cloned and named AwSeGPx, and temporal expressions derived from 2,4-DCP, 2,4,6-TCP and PCA exposure were determined by quantitative real-time PCR.

\section{Materials and methods}

\subsection{Ethics statement}

All handling methods of clams were conducted in accordance with the guidelines on the care and use of animals for scientific purposes set up by the Institutional Animal Care and Use Committee of Nanyang Medicine College, Nanyang, China.

\subsection{Materials}

Approximately 1-year-old of clams $A$. woodiana (shell length, $6.5 \pm 0.5 \mathrm{~cm}$ ) were obtained from the Baihe River of Nanyang, Henan Province, China. Prior to experiment, animals were maintained in a recirculation system containing filtered freshwater at $24{ }^{\circ} \mathrm{C}$ for 2 weeks in laboratory. 2,4-DCP, 2,4,6-TCP and PCP were purchased from Sigma-Aldrich (Sigma-Aldrich, St. Louis, MO) and stock solutions were prepared by dissolution in dimethylsulfoxide (DMSO). The experiment was conducted in rectangular plastic boxes ( $40 \mathrm{~cm} \times 25 \mathrm{~cm} ; 10 \mathrm{~cm}$ height) containing $10 \mathrm{~L}$ artificial pond water and the concentration of DMSO in the water was not excess $0.01 \%$. Clams A. Woodiana were randomly grouped into CPs treated groups in which animals were respectively administrated with 5 test concentrations of 2,4-DCP, 2,4,6-TCP and PCP, and control group with similar volume DMSO. Concentration ranges for viability studies were as follows: $60 \mu \mathrm{g} / \mathrm{L}, 120 \mu \mathrm{g} / \mathrm{L}, 240 \mu \mathrm{g} / \mathrm{L}$, $480 \mu \mathrm{g} / \mathrm{L}, 960 \mu \mathrm{g} / \mathrm{L}$ for 2,4-DCP, $50 \mu \mathrm{g} / \mathrm{L}, 100 \mu \mathrm{g} / \mathrm{L}, 200 \mu \mathrm{g} / \mathrm{L}, 400 \mu \mathrm{g} / \mathrm{L}$, $800 \mu \mathrm{g} / \mathrm{L}$ for $2,4,6-\mathrm{TCP}$, and $20 \mu \mathrm{g} / \mathrm{L}, 40 \mu \mathrm{g} / \mathrm{L}, 80 \mu \mathrm{g} / \mathrm{L}, 160 \mu \mathrm{g} / \mathrm{L}$, $320 \mu \mathrm{g} / \mathrm{L}$ for PCP. Each group had triplicates per 10 clams and those were not fed during the study. Survival in each box was assessed at48 $\mathrm{h}$ and median lethal concentration (LC50) value was calculated using the log-probit method.

In order to determine the tissue distribution of AwSeGPx, several of tissues including foot, gill, hepatopancreas, adductor muscle, heart and mantle were sampled prior to the treatment. According to above mentioned way of animal treatment, 440 clams were selected to determine the expressions of AwSeGPx. Hepatopancreas, gill and hemocytes were pooled at $0,6,12,24$ and $48 \mathrm{~h}$, then immediately frozen in liquid nitrogen and stored at $-80^{\circ} \mathrm{C}$ until total RNA extraction.

\subsection{Total RNA isolation and reverse transcription}

Total RNA was extracted using TRIzol (Invitrogen Life Technologies, USA) according to the manufacturer's protocol. Quality of RNA was monitored by $1.2 \%$ agarose gel electrophoresis and those with complete rRNA bands were selected to produce cDNA. Firststrand cDNA was synthesized using M-MLV First-Strand cDNA synthesis Kit (Takara, China) according to the manufacturer's instructions and used as the template for PCR reaction.

\subsection{Cloning of AwSeGPx cDNA}

GPx fragment was amplified using two degenerate primers G1 and G2 (Table 1), which were designed according to conserved domains of SeGPx of other species including bivalve, gastropod, insect, crustacean and vertebrate. The PCR products were subcloned into the pMDT-19 (Takara, China), sequenced from both directions (Invitrogen Life Technologies, China) and identified SeGPx partial cDNA sequence. Highly stringent primers (Table 1) designed from the partial cDNA sequences were used to characterize the $5^{\prime}$ and $3^{\prime}$ regions of the AwSeGPx cDNA by rapid amplification of cDNA ends (RACE) approaches (Takara, China) according to the manufacturer's protocol. 5' Raceouter primer and GPx5-1 (Table 1) were used for the first-round PCR of AwSeGPx 5' RACE, 3' Raceouter

\section{Table 1}

Description of the primes used in this study. G1 and G2 were degenerate primers and used to isolate partial cDNA of SeGPx. 5' Race Outerprimer, 5' Race Innerprimer GPx5-1 and GPx5-2 were used to characterize the 5' RACE of the AwSeGPx in the nest PCR, 3' Race Outerprimer, 3' Race Innerprimer, GPx3-1 and GPx3-1 for 3' RACE. GPx-F and GPx-R as well as $\beta-F$ and $\beta-R$ were selected to isolate AwSeGPx and $\beta$ actin in real-time PCR, respectively.

\begin{tabular}{|c|c|}
\hline Primer & Sequence $\left(5^{\prime}-3^{\prime}\right)$ \\
\hline G1 & TTGTAGCCNGTCTNCCCAGG \\
\hline $\mathrm{G} 2$ & GTGTCGNCTGAGANGTAATAGAA \\
\hline 5'Race Innerprimer & CATGGCTACATGCTGACAGCCTA \\
\hline 5'Race Outerprimer & CGCGGATCCACAGCCTACTGATGATCAGTCGATG \\
\hline GPX5-1 & TCCTTCTCATCGTGGTGCA \\
\hline GPx5-2 & ACCACGCCAAACTTGCCCT \\
\hline 3'Race Outerprimer & TACCGTCGTTCCACTAGTGATTT \\
\hline 3'Race Innerprimer & CGCGGATCCTCCACTAGTGATTTCACTATAGG \\
\hline GPx3-1 & CCTGAAATTCTCCAGCATATG \\
\hline GPX3-2 & ATCCTGCGACCCAGACACTG \\
\hline GPX-F & CGTTGAAGTATGTGCGACCTGG \\
\hline GPX-R & GCCATCAGGAGCAATCAGGAAC \\
\hline$\beta-F$ & САTСССТTGСТССТССААСТАTG \\
\hline$\beta-R$ & CTGGAAGGTAGAGAGAGAAGCCAAG \\
\hline
\end{tabular}


primer and GPx3-1 (Table 1) for 3' RACE. Subsequently, 5' nested PCR was performed by the $5^{\prime}$ first-round PCR product used as template, $5^{\prime}$ Raceinner primer included in the kit and GPx5-2, 3' nested PCR using $3^{\prime}$ first-round PCR products, $3^{\prime}$ Raceinner primer and GPx3-2 (Table 1). The 5' RACE and 3' RACE nest PCR products were cloned and five clones were sequenced using the method described above.

\subsection{Sequence and phylogenetic analysis}

AwSeGPx sequence was analyzed and compared using the BLAST program with a GenBank database search (www.ncbi.nlm. nih.gov/blast). The signal peptide was predicted by signal program (http://www.cbs.dtu.dk/services/SignalP). Prediction of protein domain was carried out with the Simple Modular Architecture Research Tool (http://smart.embl-heidelberg.de/). The SECIS element and stem loop structure was predicted and generated by a SECISearch 2.19 program (http://genome.unl.edu/SECISearch.html). Multiple sequence alignments of AwSeGPx gene were performed using the DANMEN analysis program. Prediction of AwSeGPx3-D structure was fulfilled by Swiss-model (http://swissmodel.expasy. org/). Phylogenetic trees constructed from the alignment were generated by the Neighbor-joining method using MEGA5.0 software. Reliability of trees obtained was assessed by bootstrapping, using 1000 bootstrap replications.

\subsection{Quantification of AwSeGPx expression by real-time PCR}

To determine the mRNA levels of AwSeGPx derived from hepatopancreas and other tissues, real-time quantitative PCR was underdone following the manufacture instruction of SYBR Premix Ex TaqTM (TaKaRa, China). Firstly, AwSeGPx primers as well as $\beta$ actin primers (Table 1 ) were designed based on isolated sequences of $A$. Woodiana, respectively, used to isolated target genes in common PCR instrument, and only one band was detected in the PCR production by agarose gel electrophoresis. PCR products were sequenced and identified as the partial sequence of target genes. Subsequently, real-time PCR was fulfilled using an ABI 7500 RealTime Detection System (Applied Biosystems, USA). Based on constructed standard curve, expression levels of AwSeGPx were calculated by $2^{-\Delta \Delta C T}$, and the data obtained were subjected to the statistical analysis followed by an unpaired sample $t$-test. Significant difference was accepted at $P<0.05$.

\section{Results}

\subsection{Molecular characterization of AwSeGPx cDNA}

A 870 bp nucleotide sequence represented the cDNA sequence of AwSeGPx was cloned and deposited in GenBank under accession number KU821031. The full-length cDNA of AwSeGPx had a 5'untranslated region (UTR) of $36 \mathrm{bp}$, a 3'UTRof $69 \mathrm{bp}$, and an open

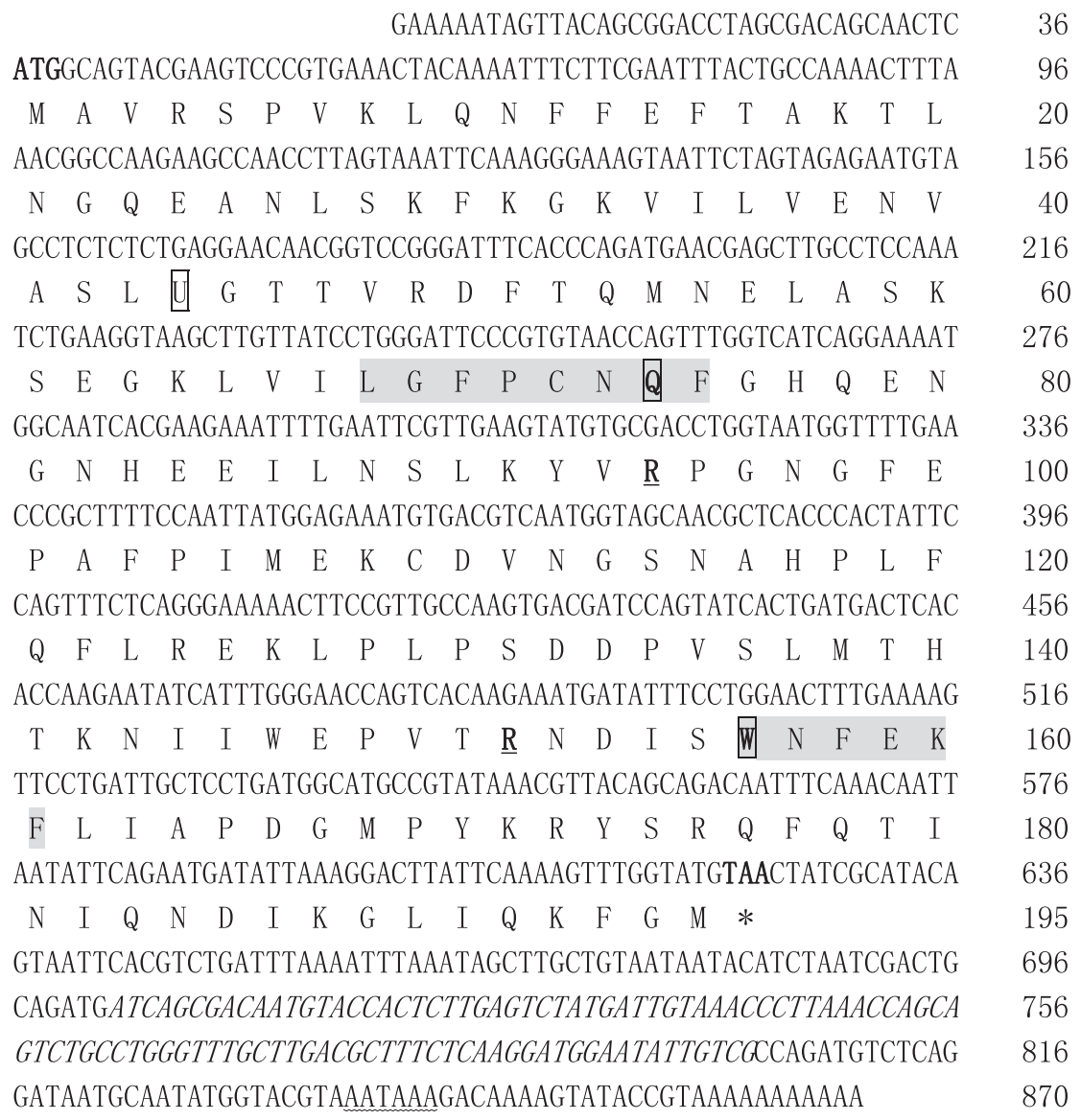

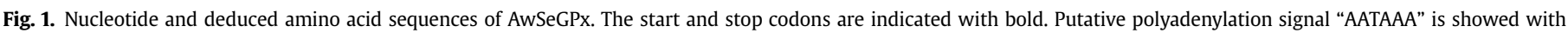



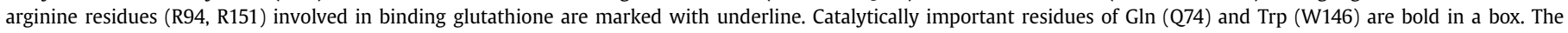
predicted SECIS element in the $3^{\prime}$ UTR is marked with italic. 
reading frame (ORF) of $585 \mathrm{bp}$ encoded a polypeptide of 195 amino acids with an estimated molecular mass of $22.04 \mathrm{kDa}$ and theoretical isoelectric point of 8.70 (Fig. 1). Termination signal (AATAAA) was located at the positions $838-843$ in the $3^{\prime}$ UTR. A codon (165TGA167) encoded Sec amino acid as $U$ was observed in predicted amino acids sequence of AwSeGPx, which is the main characteristic feature of the Se-GPx family. Result of SignalP 3.0 program showed AwSeGPx had no signal peptide in predicted animo acid sequence. In the N-terminal region, AwSeGPx had a conserve domain of GPX consisted of 8 amino acid (68LGFPCNQF75) and a glutathione peroxide-1 GPx active site (32GKVILVENVASLUGTT47) (Fig. 1). In addition, an extra active site motif (156WNFEKF161), two amino acids residues $\mathrm{Gln}(\mathrm{Q} 74)$ and two Trp residues (W156) responded for fixation of Se as well as two arginine residues (R94, R151) for directing donor glutathione substrate towards the catalytic center in GPx were also fund in AwSeGPx (Fig. 2). Furthermore, the predicted secondary structure of AwSeGPx protein contained eight $\langle$ alpha $\rangle$-helices and seven $\langle$ beta $\rangle$ sheets (Fig. 3A) that was very similar to that of Se-GPx secondary structure of other species, especially to SeGPx of Homo sapiens. The alignments of AwSeGPx 3-D structure showed a high-degree similarity with that of Se-GPx (Fig. 3B).

\subsection{SECIS element comparison and stem-loop structure of AwSeGPx}

The nucleotide sequence of AwSeGPx was analyzed by SECISearch 2.19 for occurrence of stem-loop structure resembling SECIS element. Results showed that a 101-bp SECIS element appeared in the AwSeGPx 3'UTR, which formed a stem loop secondary structure in the mRNA. Predicted secondary structure of the AwSeGPX SECIS element were composed of two helixes separated by an internal loop, a SECIS core structure, a quartet located at the base of helix 2 , and an apical loop (Fig. 4). The quartet, the main functional site of the stem loop structure, was formed by four non-Watsone Crick interacting base pairs. The SECIS elements were predicted in AwSeGPx including of UAUGAU in the $5^{\prime}$ stem, AA in the internal loop, and the UGA in the $3^{\prime}$ stem (Fig. 4).

\subsection{Evolutionary relationship of AwSeGPx}

BLAST analysis revealed that AwSeGPx matched closely with other GPX V family members. The overall deduced amino acid sequence of AwGRX exhibited $85.64 \%$ identity to Hyriopsis cumingii, $64.80 \%$ to Danio rerio and $30.26 \%$ to Haliotis discus discus. To establish the molecular evolutionary relationship of AwSeGPx, a phylogenetic trees were generated by the MEGA 5.0 neighbor joining method using different Se-GPx orthologs selected from vertebrate and invertebrate species respectively (Fig. 5). AwSeGPx was closest to that of mollusk clusters, then vertebrate, last insect and crustacean (Fig. 5). In evidenced sequences of mollusk, the most relationship of evolution with AwSeGPx was the calm of fresh water, then shellfish and snail of sea. The phylogenetic analysis of AwSeGPx reflects early divergence and independent evolution from other ASeGPxs.

\author{
Anodonta woodnatia \\ Danio rerio \\ Octopus vulgaris \\ Rattus norvegicus \\ Homo sapiens
}

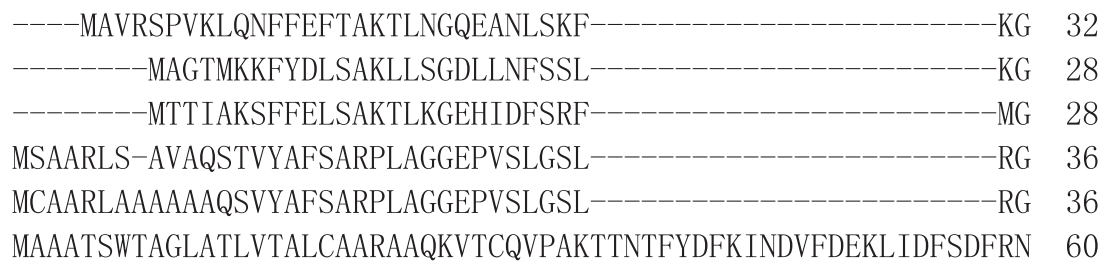

Anodonta woodnatia

KVILVENVASLUGTTVRDFTQMNELASKSEGK-LVILGFPCNQFGHQEN-GNHEEILNSL KVVLIENVASLUGTTVRDYTQMNELHSRYADQGLVVLGAPCNQFGHQEN-CKNEEILQSL KVILVENVASLUGGTTRDYMQMNKLVSQFADK-LVVLGFPCNQFGFQEN-GNGEEILLSL KVLLIENVASLUGGTTRDYTEMNDLQKRLGPRGLVVLGFPCNQFGHQEN-GKNEEILNSL 95 KVLLIENVASLUGGTVRDYTQMNELQRRLGPRGLVVLGFPCNQFGHQEN-AKNEEILNSL 95

Rattus norvegicus Homo sapiens KVVLIVNVATYUGGHTQYNGLNALMTDYAGQGDFLVLGLPCNQFLKQEPGANGTEIMNGV 120

Anodonta woodnatia

Danio rerio

KYVRPGNGFEPAFPIMEKCDVNGSNAHPLFQFLREKLPLPSDDPVSLMTHTKNIIWEPVT 150

Octopus vulgaris

Rattus norvegicus

Homo sapiens KYVRPGNGFEPKFQILEKLEVNGENAHPLFAFLKEKLPQPSDDPVSLMGDPKFIIWSPVC 147 QSVRPGNGFKPNFTIMEKVEVNGENTHAVFQFLKNHLPYPSDDSTSFMKNPSSINWTPVA 146 KYVRPGGGFEPNFTLFEKCEVNGEKAHPLFTFLRNALPAPSDDPTALMTDPKYIIWSPVC 155 KYVRPGGGFEPNFMLFEKCEVNGAGAHPLFAFLREALPAPSDDATALMTDPKLITWSPVC 155 Haliotis discus discus KYVRPGLT--PLFNLTQKIDVNGEHQHPLYRFLKSYCKRVESVFRPSN----LLFYEPKE 174

Anodonta woodnatia

Danio rerio

RNDISWNFEKFLIAPDGMPYKRYSRQFQTINIQNDIKGLIQKFGM---

195 RNDISWNFEKFLIGPDGEPFKRYSRRFLTIDIDADIKELLKRTK----

191 RNDISWNFEKFLIAPDGKPFLRYSKSFQTIEIQKDIKSLIEKFS---- 190 RNDISWNFEKFLVGPDGVPVRRYSRRFRTIDIEPDIEALLSKQPSNP- 202 RNDVAWNFEKFLVGPDGVPLRRYSRRFQT IDIEPDIEALLSQGLSCA- 202 Rattus norvegicus Homo sapiens

Haliotis discus discus IGDVYWNFEKFLVGADGHVKFRYSLEVQPIDVRPDIEALLGRHVPVVG 222

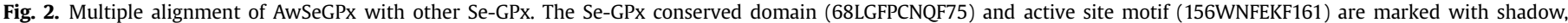

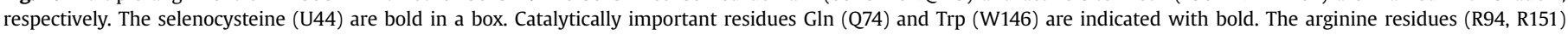
involved in binding glutathione are highlighted in a line. 

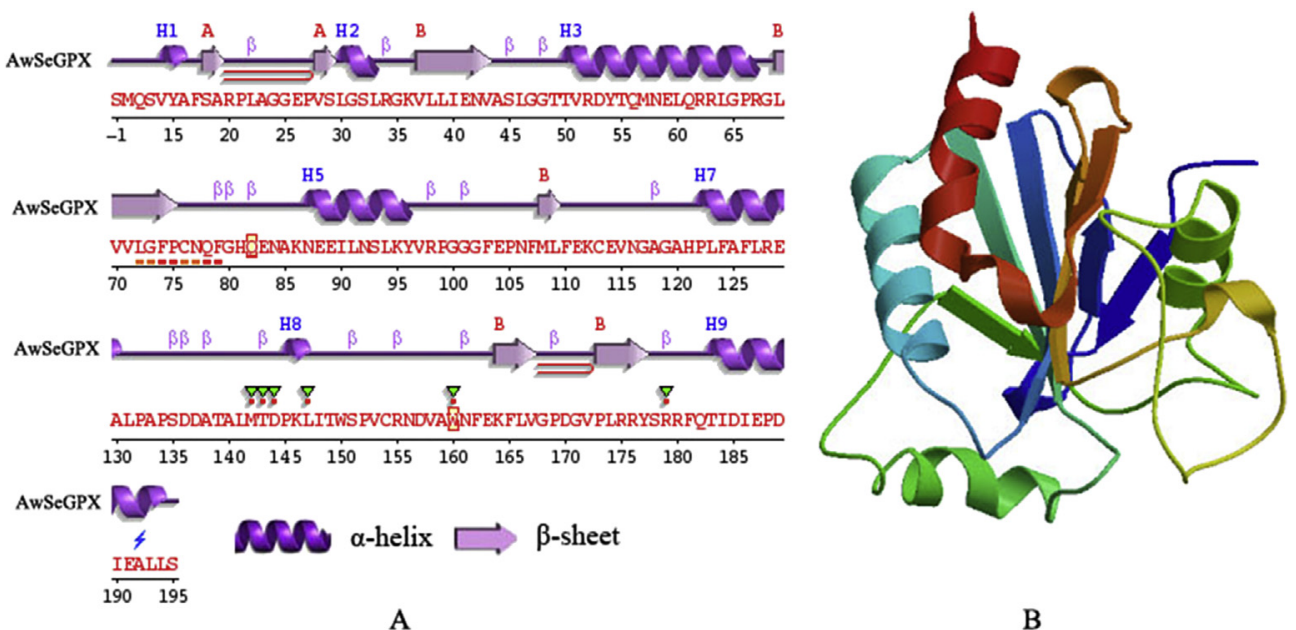

Fig. 3. Predicted secondary and 3D structures of AwSeGPx deduced amino acids. A: The secondary structure of AwSeGPx. B: The 3D structure of AwSeGPx.

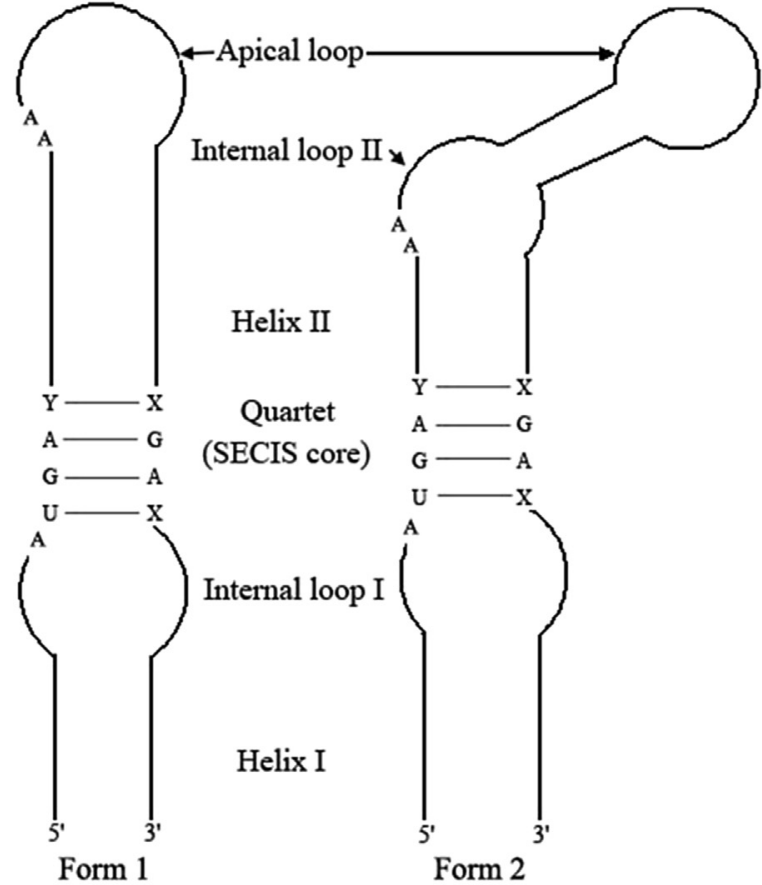

A

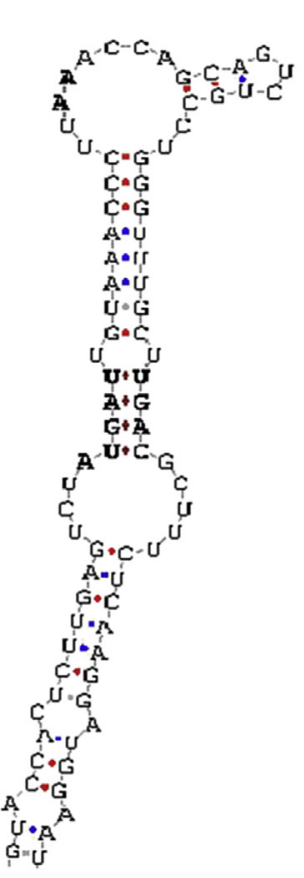

B

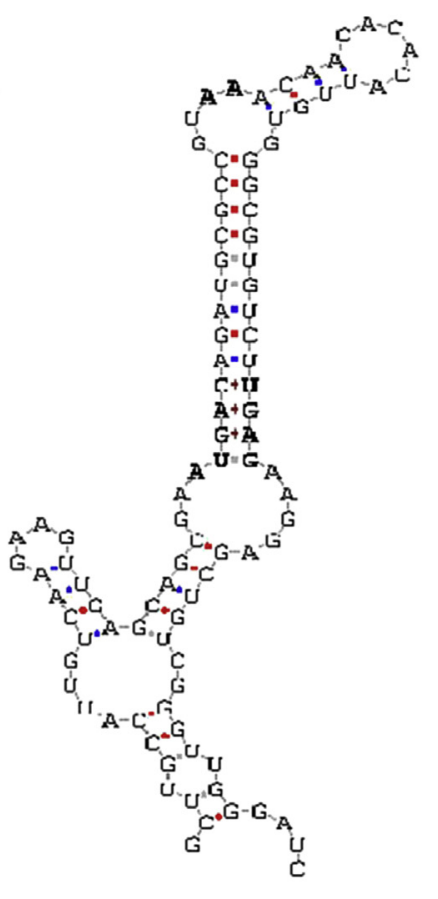

C

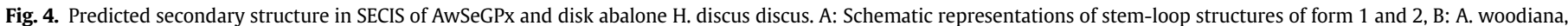
C: H. discus discus. Conserved nucleotides in the SECIS core (Quartet) and apical loop are shown in bold.

\subsection{Tissue distribution of AwSeGPx}

Results of real time PCR showed that expressions of AwSeGPx had widely distribution including foot, gill, hepatopancreas, adductor muscle and mantle (Fig. 6). The mRNA levels of AwSePGPx showed a higher level in the hepatopancreas and heart, a moderate level in mantle, foot and gill, but a lower level in adductor muscle (Fig. 6).

\subsection{Acute toxicity}

Dead calms in each box was determined at $48 \mathrm{~h}$ and LC50 value were calculated using the log-probit method, data indicated the LC50 of 2,4-DCP,2,4,6-TCP and PCP was $0.246,0.194$ and $0.139 \mathrm{mg} /$ L33 for $A$. woodiana, respectively (Table 2 ).

\subsection{Temporal expressions of AwSePGPx in hepatopancreas exposured to 2,4-DCP,2,4,6-TCP, and $P C P$}

Temporal expressions of AwSePGPx mRNA in hepatopancreas were significantly affected by $2,4-\mathrm{DCP}, 2,4,6-\mathrm{TCP}$, and PCP challenge using RT-qPCR with $\beta$-actin as internal control (Fig. 7). In all the 2,4DCP treated groups $(60,120,240,480$ and $960 \mu \mathrm{g} / \mathrm{L})$, mRNA levels of AwSeGPx increased more than 1.79 times $(P<0.05)$ from $6 \mathrm{~h}$ to $48 \mathrm{~h}$ compared with that of control group. In all the 2,4,6-TCP treated groups $(50,100,200,400$ and $800 \mu \mathrm{g} / \mathrm{L})$ at $6,12,24$ and $48 \mathrm{~h}$, except of $50 \mu \mathrm{g} / \mathrm{L}$ of 2,4,6-TCP at $6 \mathrm{~h}$, AwSeGPx mRNA levels in others exhibited a significant up-regulation in contrasted with that of control group, which increased more than 1.01 times (Fig. 7).

In the PCP treated groups $(20,40,80,160$ and $320 \mu \mathrm{g} / \mathrm{L})$, at 6,12 and $24 \mathrm{~h}$ post exposure, expressions of AwSeGPx were significantly 


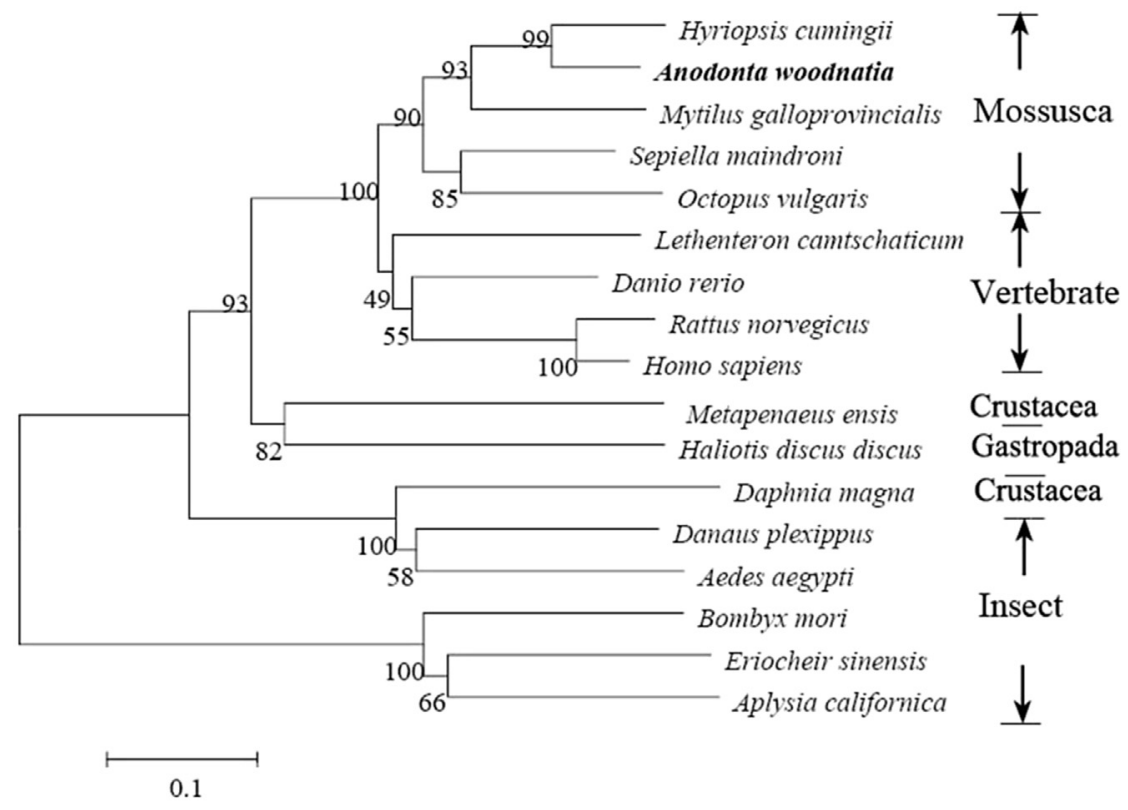

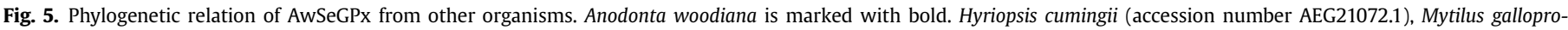

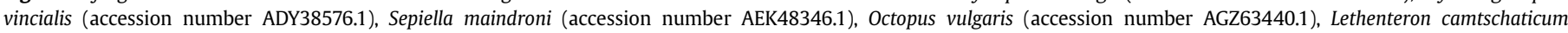

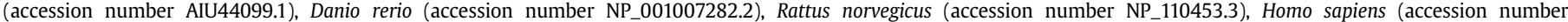

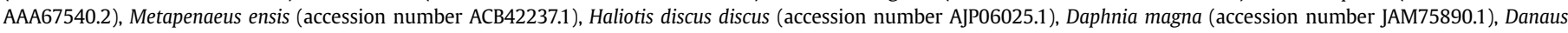

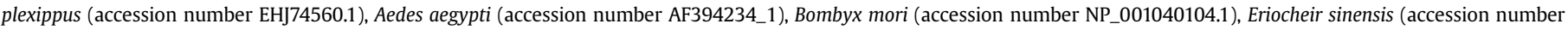
ACV41935.1), Aplysia californica (accession number NP_001191508.1).

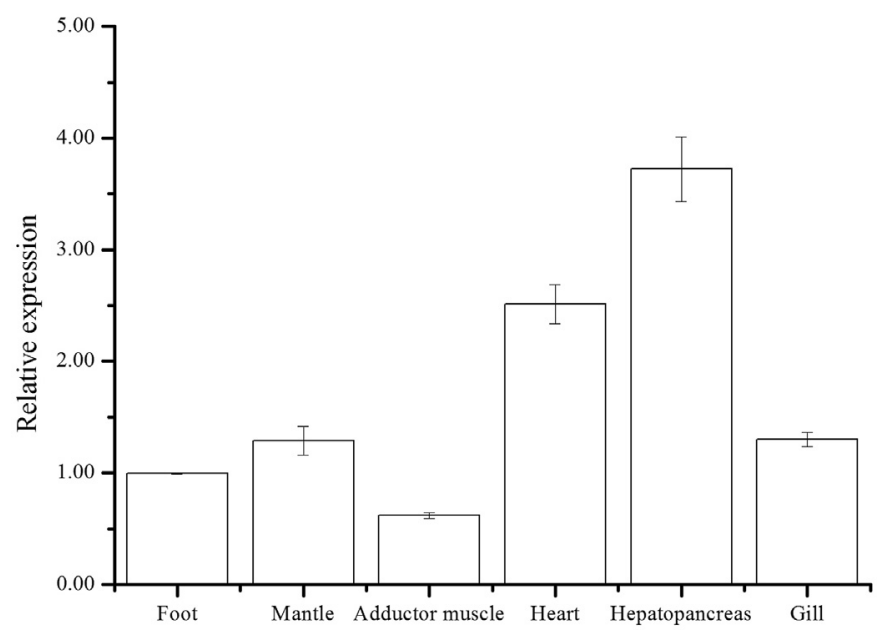

Fig. 6. Real-time PCR analysis of AwSeGPx transcript from different tissues. $n=3$ replicates.

Table 2

48 h LC50 values for $A$. Woodiana exposed to 2,4-DCP, 2,4,6-TCP and PCP.

\begin{tabular}{llll}
\hline PCs & LC50 $(\mathrm{mg} / \mathrm{L})$ & \multicolumn{2}{l}{$95 \%$ Confidence intervals } \\
\cline { 3 - 4 } & & Lower & Upper \\
\hline $2,4 \mathrm{DCP}$ & 0.246 & 0.1905 & 0.3185 \\
$2,4,6 \mathrm{TCP}$ & 0.194 & 0.1520 & 0.2487 \\
PCP & 0.139 & 0.1003 & 0.2180 \\
\hline
\end{tabular}

induced compared with that of control group (Fig. 7). At $48 \mathrm{~h}$, the significant up-regulations were still observed in 20, 40, $80 \mu \mathrm{g} / \mathrm{L} \mathrm{PCP}$ treated groups. But, in 160 and $320 \mu \mathrm{g} / \mathrm{L}$ PCP treated groups, the expression of AwSeGPx declined and returned to normal level at
48 h (Fig. 7).

\subsection{Temporal expressions of AwSePGPx in gill and hemocytes exposured to 2,4-DCP,2,4,6-TCP, and $P C P$}

In all the 2,4-DCP, 2,4,6-TCP and PCP treated groups, expressions of AwSePGPx mRNA in gill were significantly induced from $6 \mathrm{~h}$ to $48 \mathrm{~h}$. Meanwhile, at $48 \mathrm{~h}$ of post exposure, the significant upregulation of AwSePGPx showed a decline trend that was observed in the 2,4,6-TCP treated groups (200, 400 and $800 \mu \mathrm{g} / \mathrm{L})$ and PCP treated groups (160 and $320 \mu \mathrm{g} / \mathrm{L}$ ) (Fig. 8) in contrasted with that of previous sampled time.

In the hemocytes, expressions of AwSePGPx mRNA were obviously effected by 2,4-DCP, 2,4,6-TCP, and PCP treatment. A doseand time-dependant up-regulation of AwSePGPx expression was observed in 2,4-DCP treated groups (60, 120 and $240 \mu \mathrm{g} / \mathrm{L}), 2,4,6$ TCP treated groups (50, 100 and $200 \mu \mathrm{g} / \mathrm{L})$ and PCP treated groups $(20,40$ and $80 \mu \mathrm{g} / \mathrm{L})$. However, expressions of AwSePGPx showed a biphasic profile characterized by up-regulation trend in the early stage and down-regulation trend in the latter stage at $48 \mathrm{~h}$ in higher concentration groups, such as 2,4-DCP treated groups (480 and $960 \mu \mathrm{g} / \mathrm{L}$ ), 2,4,6-TCP treated groups (400 and $800 \mu \mathrm{g} / \mathrm{L}$ ) and PCP treated groups (160 and $320 \mu \mathrm{g} / \mathrm{L}$ ) (Fig. 9).

\section{Discussion}

The coding sequence of AwSeGPx cDNA contained a nonsense TGA, suggesting AwSeGPx is a member of Se-GPx family. This codon is firstly indicated to encode a selenocysteine for in mouse, subsequently in human and rat $[25,26]$. Now, the codon is widely observed in Se-GPx of mollusk, such as bivalve Dreissena polymorpha, scallop Mizuhopecten yessoensis, clam V. philippinarum, and disk abalone $H$. discus discus $[21,22,27]$. So, the selenocysteine is identified as the catalytic site in this enzyme from invertebrate to vertebrate. 
A
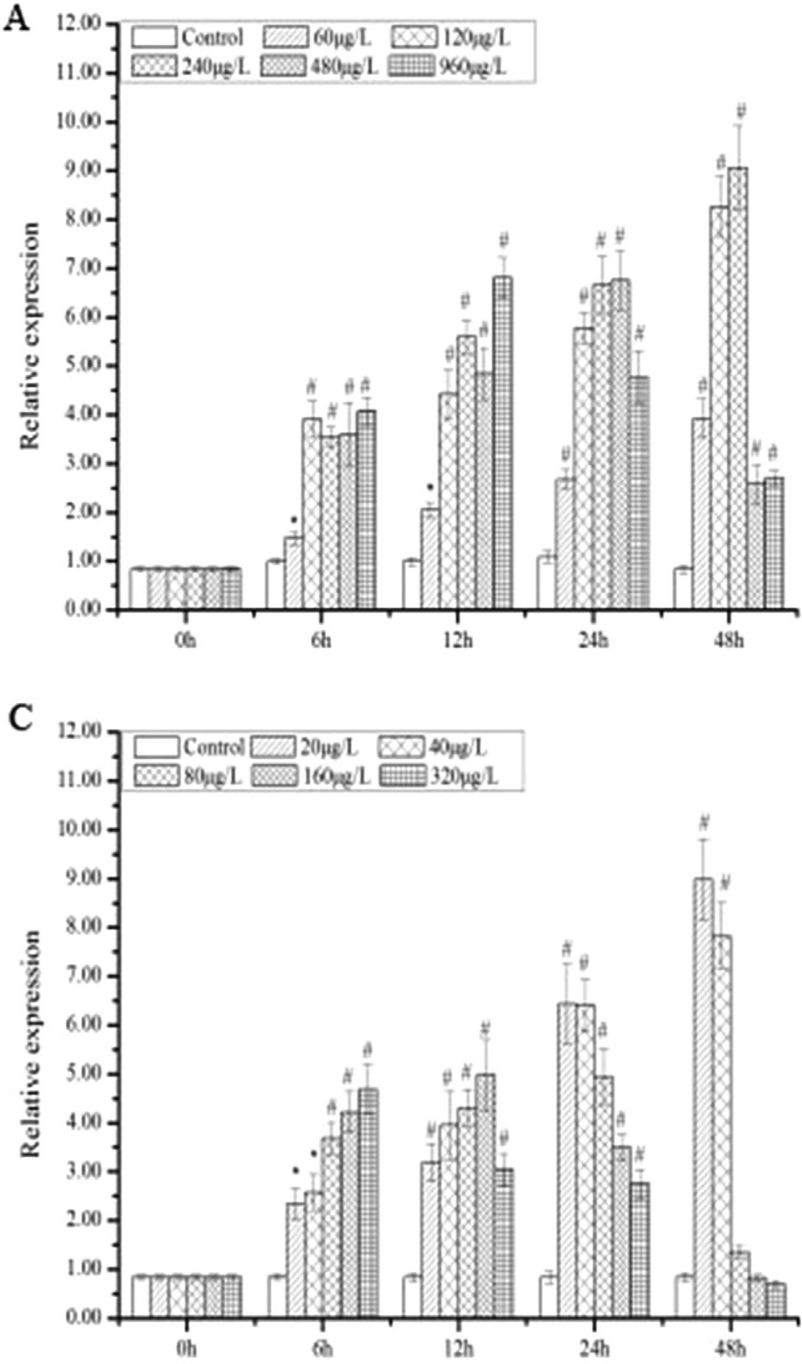

B

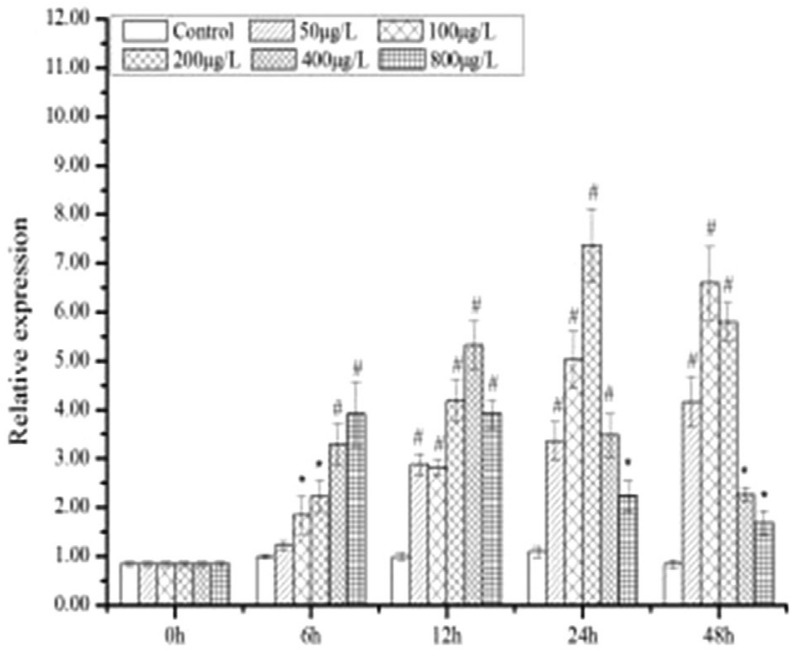

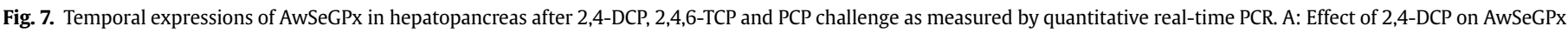

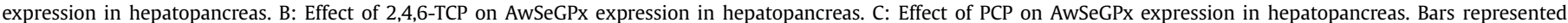
means \pm SE; $\mathrm{n}=3$ /each group/each time point. ${ }^{*} P<0.05,{ }^{\#} P<0.01$ vs control group at the same time.

Two conserved motifs of Se-GPx family were also fund in the deduced amino acids sequence of AwSeGPx, one was the Se-GPx signature 2 at 67LGFPCNQF75, and another was the active site at156WNFEKF161. In the two domains, $G \ln (\mathrm{Q})$ and $\operatorname{Trp}(\mathrm{W})$ are considered as important residues for GPx catalytic activity, and involved in the fixation of selenium [28]. In addition, results multiple alignment showed two arginine residues of AwSeGPx at position 94 and 151 have a high homology with that of other Se-GPx in which these arginine residues are contribute to the electrostatic architecture that directs the donor substrate (glutathione) towards the catalytic center in such a way that its sulfhydryl group must react with the selenium [28]. Therefore, to shed light of functions of these conserved residues is an interesting subject to understand the AwSeGPx role.

The SECIS element is a major characteristic feature of the mRNA sequence of Se-GPxs, which directs the SeC into the UGA opal codon during the translation process [29]. Length of SECIS elements of AwSeGPx had $101 \mathrm{bp}$ which are composed of two helixes separated by an internal loop I, a SECIS core structure, a quartet located at the base of helix 2, an apical loop, and an internal loop II (stemloop). According to stem-loop secondary structure, the location of a conserved stretch of two or three adenosines (A), and the size of the apical loop, SECIS elements are grouped into two main forms, form 1 and form 2. Inform 1, the AA stretch is located at the apical loop, whereas inform 2, this stretch is shifted to an internal loop II region [30]. Therefore, SECIS element of AwSeGPx belongs to the member of form 2 SECIS elements with respect with AA located of internal loop II. However, additional experiments are required to determine the real function of the stem-loop structure of the SECIS element in AwSeGPx.

AwSeGPx showed a widely distribution in gill, mantle, abductor muscle, foot, heart and hepatopancreas. Ubiquitous distribution suggests that AwSeGPx is an important enzyme for the tissues to keep the balance of redox. The variation of AwSeGPx mRNA levels in different tissues is associated with the balance of various processes acting on the production of ROS generated in different environment. In selected tissues, the highest level was observed in hepatopancreas that is related to the roles of hepatopancreas as the main metabolic organ and the main defense tissue against oxidative stress [31].

There are relatively fewer published reports providing sensitivity of freshwater bivalve responded to organic compounds. In the 
A
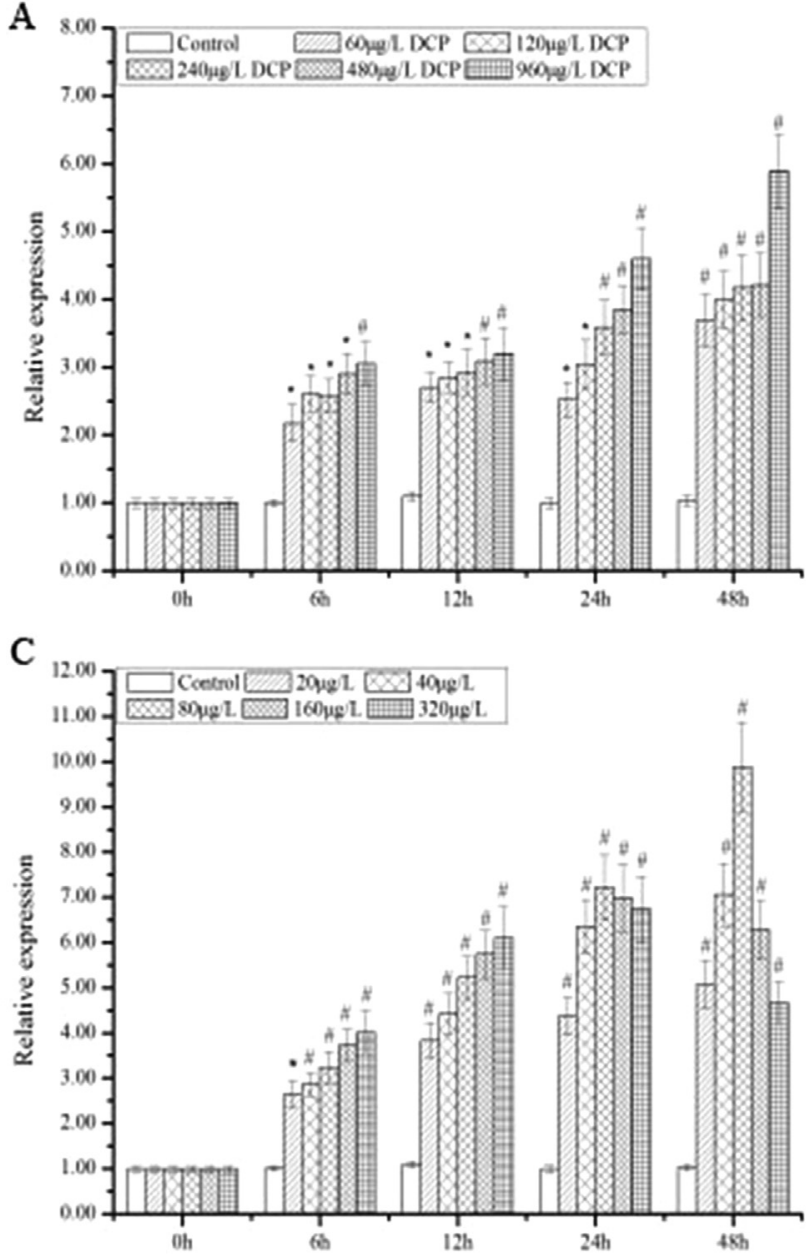

B

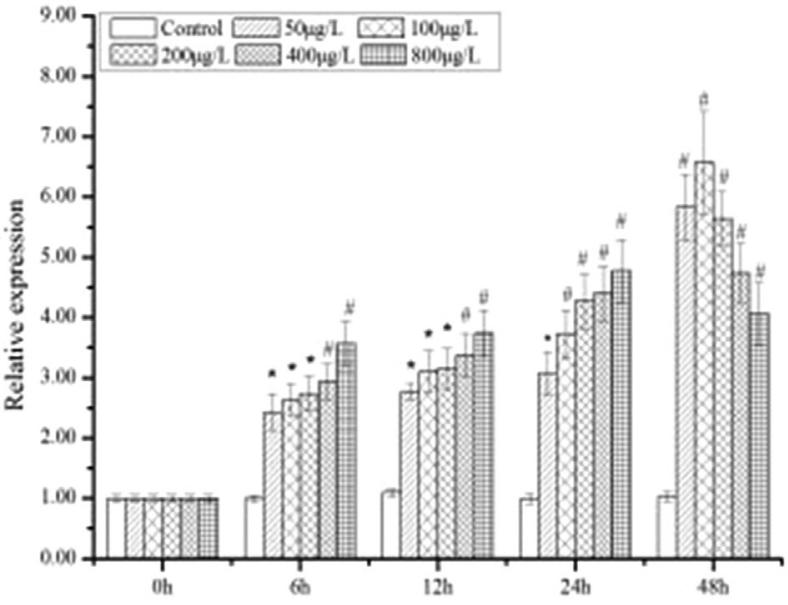

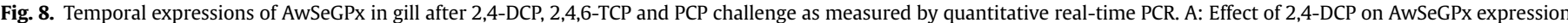

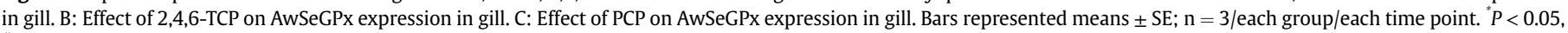
${ }^{\#} P<0.01$ vs control group at the same time.

present study, 2,4-D, 2,4,6-TCP, and PCP were the three organic chemicals that elicited bivalve $A$. woodiana responses, LC50 results showed clams are more sensitive to PCP exposures than other ones. In the crustacean Daphnia magna, results of EC/LC50show PCP is more potently toxic than that of 2,4-DCP and 2,4,6-TCP [1]. In addition, the recommended acute exposure water quality criteria are $286.2 \mu \mathrm{g}$ 2,4-DCP/L, $341.5 \mu \mathrm{g}$ 2,4,6-TCP/L and $11.4 \mu \mathrm{g} \mathrm{PCP} / \mathrm{L}$ at $\mathrm{pH}$ 7.8, and chronic ones are $16.3 \mu \mathrm{g} 2,4-\mathrm{DCP} / \mathrm{L}, 54.6 \mu \mathrm{g} 2,4,6-\mathrm{TCP} / \mathrm{L}$ and $3.9 \mu \mathrm{g} \mathrm{PCP} / \mathrm{L}$ [1]. Therefore, implying TCP likely exhibits more severe destroy for water organisms than that of 2,4-DCP and 2,4,6TCP under similar environment. As to the reason, that is likely with the transformation of $\mathrm{PCP}$ in the tissue. It has indicated that oxidative dechlorination what PCP is catalyzed by cytochrome P450 enzymes to form tetrachlorohydroquinone (TCHQ) can result in oxidative stress on cells and tissues [32]. Meanwhile, TCHQ is considered as a more toxic metabolic product of $\mathrm{PCP}$, it can induce DNA strand breakage and deplete glutathione content [33,34]. In order to explore of mechanism of PCP action in the bivalve, great efforts are required in the future.

In hepatopancreas, gill and hemocytes, administration of different concentrations of 2,4-DCP, 2,4,6-TCP as well as PCP could result in a significant up-regulation of AwSeGPx expressions in contrast with that of control group, suggest enhancement of AwSeGPx is contribute to eliminate ROS stress derived from of 2,4-
DCP, 2,4,6-TCP and PCP challenges. As to aerobic organisms, production of ROS is a common physiological phenomenon. In healthy organism, total ROS levels are tightly controlled by an array of antioxidant enzymes to maintain a balance between ROS level and antioxidant enzyme activity [11,12]. Clams $A$. woodiana are filterfeeding freshwater bivalves $[20,23]$. PCs, as important pollutant in water, are easier to pass through the cell membrane and accumulate in body that causes an obvious increase of ROS production $[9,10]$. On the other hand, anti-oxidant enzyme expressions are induced to evaluate the scanverging capacity of ROS. Se-GPx enzyme catalyzes the reduction of hydrogen peroxide into water, or the reduction of organic peroxides to their corresponding stable alcohols by oxidizing the reduced glutathione into its oxidized form. In V. philippinarum, VpSe-GPx expressions are significantly up-regulated to against oxidative stress caused by heavy metals [22]. In disk abalone $H$. discus discus, enhancement of selenium dependent glutathione peroxidase may be involved in a protective role against $\mathrm{H}_{2} \mathrm{O}_{2}$ oxidative stress [27]. Therefore, these studies point out that the inductions of AwSeGPx expression contribute to prevent cells from injury of ROS.

Notably, in hepatopancreas and hemocytes, the AwSeGPx expression in lower concentration of 2,4-DCP, 2,4,6-TCP and PCP treated groups showed a dose- and time-dependent manner. However, in higher concentration of this three PCs treated ones 
A
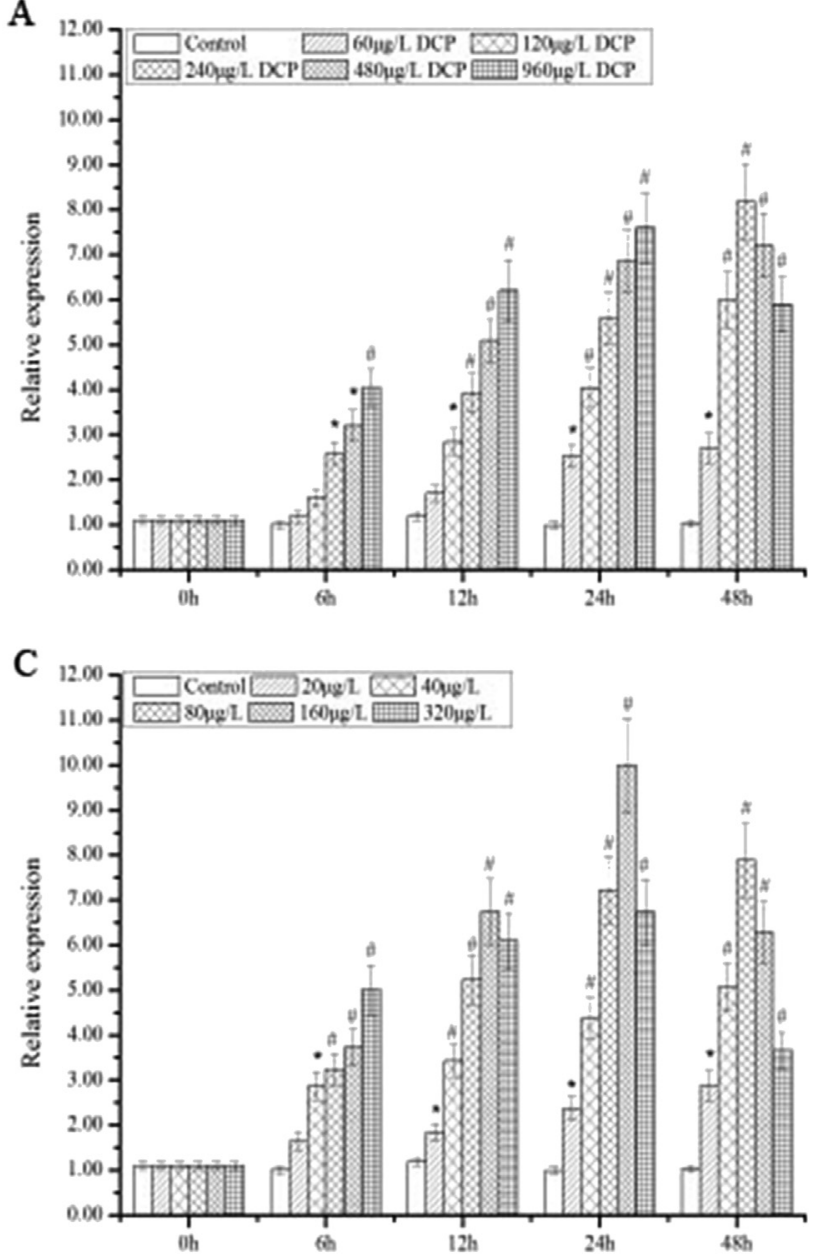

B

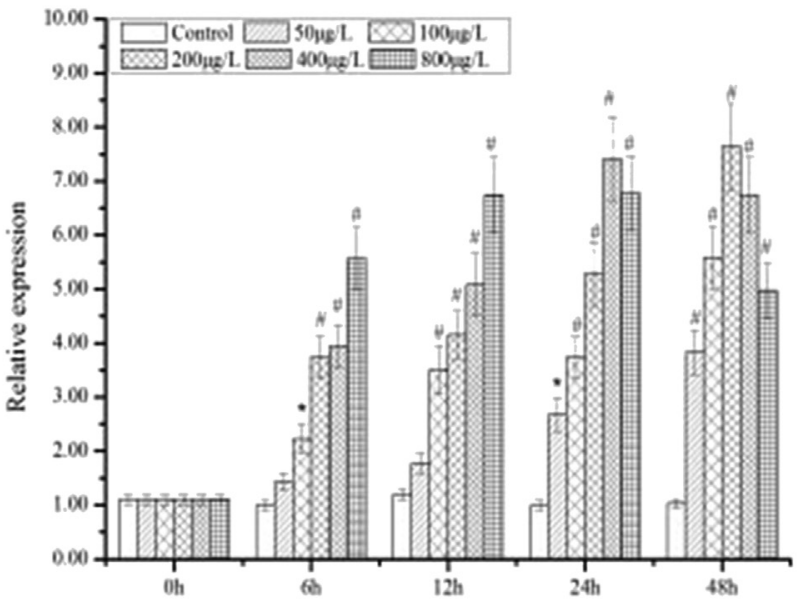

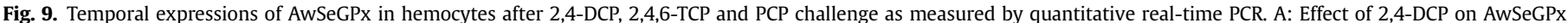

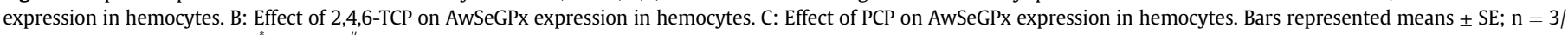
each group/each time point. ${ }^{*} P<0.05,{ }^{\#} P<0.01$ vs control group at the same time.

AwSeGPx expression showed a biphasic profile characterized by up-regulation trend in the early stage and down-regulation trend in the latter stage, such as 480 and $960 \mu \mathrm{g} / \mathrm{L}$ of 2,4-DCP treated groups, 400 and $800 \mu \mathrm{g} / \mathrm{L}$ of 2,4,6-TCP treated groups, 80, 160 and $320 \mu \mathrm{g} / \mathrm{L}$ of PCP treated groups, this pattern is associated with scavenging ability of animals faced persistent production of ROS. With elongation of 2,4-DCP, 2,4,6-TCP and PCP treated time, ROS should increasingly be produced and accumulated in the cells. On another hand, animals are enhancing anti-oxidant enzyme activities to eliminate ROS [35]. Once levels of abruptly increased ROS is exceed the eliminating ability of cells that cause redox imbalance possibly via a shift between oxidants and antioxidants in favor of oxidants, and result in chronic inflammation, apoptosis of immune cells, etc $[36,37]$. In the condition, if animals cannot produce new cells to compensate for death ones, number of living cells should be gradually decreased. Following, expressions of AwSeGPx are also decline alone treated time. Thus, a biphasic phenomenon was detected in higher concentration groups of three PCs. Similar results are also reported in other studies. For instance, in the goldfish, weak oxidative stress activates antioxidant defense mechanisms, strong oxidative stress generated when $\mathrm{Cd}$ accumulates in tissues results in a decrease in metabolic activity and reduced antioxidant enzyme mRNA expression [38,39].

At $6 \mathrm{~h}$, administration of different concentrations of 2,4-DCP, 2,4,6-TCP and PCP could result in a significant up-regulation of
AwSeGPx expression in the gill, but this scenario of significant upregulation was only occurred in higher concentration-treated groups in hepatopancreas and hemocytes. It is suggesting that the gills reflect early-phase responses as external organs in direct contact with contaminants, whereas the hepatopancreas and hemocytes reflect late-phase responses, as internal tissues. Similar results are also reported in the previous studies [26,40,41]. In addition, expressions of AwSeGPx showed different characterizations in groups treated with 2,4-DCP, 2,4,6-TCP and PCP at similar tissue as well as one compound of these PCs at different tissues. As to the phenomena, one interpretation is likely associated with the different physiological functions of these tissues. The hepatopancreas of mollusca showed double properties combined liver with pancreas, is involved in digestion, neutralizes large amounts of toxicants that are ingested by the organism and the major site of toxicants accumulation $[42,43]$. In contrast, the gills are located in the ventilated mantle cavity and direct interact with the outer environment and their epithelium is very thin $[26,40]$. Thus, the gills are also frequent target organs of environmental pollutants [44]. Hemocytes of mussels are the important line of defense against pathogenic infection as well as reducing ROS, through phagocytosis and stimulation of respiratory burst and widely used as models in environmental toxicology $[21,26]$. It is well known that heavy metals' toxicity could be a result of oxidative stress that is associated with respiratory burst processes in the induction of 
metal-mediated oxidative and genotoxic events in hemocytes of mussels $[26,45]$. Considering here, respiratory burst plays a potential role in eliminating toxic effects induced by heavy and PCs. Another interpretation is that, based on mentioned above, various toxic metabolic products generated from 2,4-DCP, 2,4,6-TCP and PCP show different toxic effects in $A$. woodiana. Therefore, many complex elements are likely involved into regulation of AwSeGPx expression in the hepatopancreas, gill and hemocytes.

In conclusion, we clone a Se-GPx cDNA from $A$. woodiana and its full-length cDNA contains highly conserved motifs and residues important for antioxidant defense that similar to other Se-GPX family proteins. Correlating the tissue specific mRNA expression and temporal expressions, suggests up-regulation of AwSeGPx are contribute to eliminate the oxidative stress derived from 2,4-DCP, 2,4,6-TCP and PCP exposure. It worth noting that PCP is likely to be more detrimental for aquatic organisms than 2,4-DCP and 2,4,6TCP under a similar environment. In order to prevent or mitigate extensive negative impacts on aquatic organisms in freshwater and conserve aquatic organism biodiversity, it would thus be of critical importance for government to take measures controlling diffusion of PCs.

\section{Acknowledgement}

This research was funded by the National Natural Science Foundation of Henan (No. 2015GGJS-286, 122102310103).

\section{References}

[1] L. Xing, H. Liu, J.P. Giesy, H. Yu, pH-dependent aquatic criteria for 2,4dichlorophenol, 2,4,6-trichlorophenol and pentachlorophenol, Sci. Total Environ. 441 (2012) 125-131.

[2] L. Xing, J. Sun, H. Liu, H. Yu, Combined toxicity of three chlorophenols 2,4dichlorophenol, 2,4,6-trichlorophenol and pentachlorophenol to Daphnia magna, J. Environ. Monit. 14 (2012) 1677-1683.

[3] M. Syc, E. Fiserova, J. Karban, M. Puncochar, V. Pekarek, The effect of transient operations on the levels and congener profiles of PCBz, PCPh and PCDD/F in raw flue gases of MSWI plant, Chemosphere 118 (2015) 261-267.

[4] C. Louis, A. Covaci, M. Stas, D.E. Crocker, G. Malarvannan, A.C. Dirtu, C. Debier, Bioaccumulation of hydroxylated polychlorinated biphenyls and pentachlorophenol in the serum of northern elephant seal pups (Mirounga angustirostris), Environ. Res. 136 (2015) 441-448.

[5] W. Zheng, H. Yu, X. Wang, W. Qu, Systematic review of pentachlorophenol occurrence in the environment and in humans in China: not a negligible health risk due to the re-emergence of schistosomiasis, Environ. Int. 42 (2012) 105-116.

[6] B.J.L. Yeo, S. Goh, J. Zhang, A.G. Livingston, A.G. Fane, Novel MBRs for the removal of organic priority pollutants from industrial wastewaters: a review, J. Chem. Technol. Biotechnol. 90 (2015) 1949-1967.

[7] W.M. Zhou, D.Q. Fu, Z.G. Sun, List for priority pollutants in waters, Environ. Monit. China 6 (1990) 1-3 [in Chinese].

[8] B.L. Lei, S.B. Huang, X.W. Jin, Z. Wang, Deriving the aquatic predicted no-effect concentrations (PNECS) of three chlorophenols for the Taihu Lake, China, J. Environ. Sci. Health Part A-Toxic/Hazard. Subst. Environ. Eng. 45 (2010) $1823-1831$.

[9] D. Yin, Y. Gu, Y. Li, X. Wang, Q. Zhao, Pentachlorophenol treatment in vivo elevates point mutation rate in zebrafish p53 gene, Mutat. Res.-Genet. Toxicol. Environ. Mutagen. 609 (2006) 92-101.

[10] X. Zhang, X. Zhang, Z. Niu, Y. Qi, D. Huang, Y. Zhang, 2,4,6-trichlorophenol cytotoxicity involves oxidative stress, endoplasmic reticulum stress, and apoptosis, Int. J. Toxicol. 33 (2014) 532-541.

[11] A. Bigot, P. Vasseur, F. Rodius, SOD and CAT cDNA cloning, and expression pattern of detoxification genes in the freshwater bivalve Unio tumidus transplanted into the Moselle river, Ecotoxicology 19 (2010) 369-376.

[12] L. Tomanek, Proteomic responses to environmentally induced oxidative stress, J. Exp. Biol. 218 (2015) 1867-1879.

[13] D. Macias-Mayorga, I. Laiz, I. Moreno-Garrido, J. Blasco, Is oxidative stress related to cadmium accumulation in the Mollusc Crassostrea angulata? Aquat. Toxicol. 161 (2015) 231-241.

[14] H. Chen, J. Zha, L. Yuan, Z. Wang, Effects of fluoxetine on behavior, antioxidant enzyme systems, and multixenobiotic resistance in the Asian clam Corbicula fluminea, Chemosphere 119 (2015) 856-862.

[15] S. Koutsogiannaki, S. Franzellitti, E. Fabbri, M. Kaloyianni, Oxidative stress parameters induced by exposure to either cadmium or 17 beta-estradiol on Mytilus galloprovincialis hemocytes. The role of signaling molecules, Aquat. Toxicol. 146 (2014) 186-195.
[16] V.L. Maria, M.J. Bebianno, Antioxidant and lipid peroxidation responses in Mytilus galloprovincialis exposed to mixtures of benzo(a)pyrene and copper Comp. Biochem. Physiol. C-Toxicol. Pharmacol. 154 (2011) 56-63.

[17] V. Chatziargyriou, S. Dailianis, The role of selenium-dependent glutathione peroxidase (Se-GPx) against oxidative and genotoxic effects of mercury in haemocytes of mussel Mytilus galloprovincialis (Lmk.), Toxicol. In Vitro 24 (2010) 1363-1372.

[18] S. Yoshimura, K. Watanabe, H. Suemizu, T. Onozawa, J. Mizoguchi, K. Tsuda, H. Hatta, T. Moriuchi, Tissue specific expression of the plasma glutathione peroxidase gene in rat kidney, J. Biochem. 109 (1991) 918-923.

[19] P.M.G. Nair, S.Y. Park, J. Choi, Characterization and expression analysis of phospholipid hydroperoxide glutathione peroxidase cDNA from Chironomus riparius on exposure to cadmium, Comp. Biochem. Physiol. B-Biochem. Mol. Biol. 163 (2012) 37-42.

[20] P. Doyen, F. Rodius, L. L'Hoste, L. Hoffmann, H.-M. Cauchie, Identification and mRNA expression of pi-class glutathione S-transferase and seleniumdependent glutathione peroxidase in the gudgeon Gobio gobio exposed to PCB 77, Comp. Biochem. Physiol. C-Toxicol. Pharmacol. 155 (2012) 300-306.

[21] L. Zhang, X. Liu, L. Chen, L. You, D. Pei, M. Cong, J. Zhao, C. Li, D. Liu, J. Yu, $\mathrm{H}$. Wu, Transcriptional regulation of selenium-dependent glutathione peroxidase from Venerupis philippinarum in response to pathogen and contaminants challenge, Fish Shellfish Immunol. 31 (2011) 831-837.

[22] P. Hliwa, B. Zdanowski, G.J. Dietrich, A. Andronowska, J. Krol, A. Ciereszko, Temporal changes in gametogenesis of the invasive Chinese pond musse Sinanodonta woodiana (Lea, 1834) (Bivalvia: Unionidae) from the Konin Lakes system (Central Poland), Folia Biol.-Krak. 63 (2015) 175-185.

[23] M. Parolini, S. Magni, S. Castiglioni, A. Binelli, Amphetamine exposure imbalanced antioxidant activity in the bivalve Dreissena polymorpha causing oxidative and genetic damage, Chemosphere 144 (2016) 207-213.

24] I. Chambers, J. Frampton, P. Goldfarb, N. Affara, W. McBain, P.R. Harrison, The structure of the mouse glutathione peroxidase gene: the selenocysteine in the active site is encoded by the 'termination' codon, TGA, Embo J. 5 (1986) 1221-1227.

[25] G.T. Mullenbach, A. Tabrizi, B.D. Irvine, G.I. Bell, R.A. Hallewell, Sequence of a cDNA coding for human glutathione peroxidase confirms TGA encodes active site selenocysteine, Nucleic Acids Res. 15 (1987), 5484-5484.

[26] M. De Zoysa, W.A. Pushpamali, C. Oh, I. Whang, S.J. Kim, J. Lee, Transcriptional up-regulation of disk abalone selenium dependent glutathione peroxidase by H2O2 oxidative stress and Vibrio alginolyticus bacterial infection, Fish Shelliish Immunol. 25 (2008) 446-457.

[27] R. Ladenstein, O. Epp, W.A. Gunzler, L. Flohé, Glutathione peroxidase on approval, Life Chem. Rep. 14 (1986) 37-55.

[28] K.D. Aumann, N. Bedorf, R. BrigeliusFlohe, D. Schomburg, L. Flohe, Glutathione peroxidase revisited - Simulation of the catalytic cycle by computer-assisted molecular modelling, Biomed. Environ. Sci. 10 (1997) 136-155.

[29] R. Walczak, E. Westhof, P. Carbon, A. Krol, A novel RNA structural motif in the selenocysteine insertion element of eukaryotic selenoprotein mRNAs, RNA-A Publ. RNA Soc. 2 (1996) 367-379.

[30] E. Grundner-Culemann, G.W. Martin, J.W. Harney, M.J. Berry, Two distinct SECIS structures capable of directing selenocysteine incorporation in eukaryotes, RNA-A Publ. RNA Soc. 5 (1999) 625-635.

[31] M. Carneiro, B. Reis, J. Azevedo, A. Campos, H. Osorio, V. Vasconcelos J.C. Martins, Glutathione transferases responses induced by microcystin-LR in the gills and hepatopancreas of the clam Venerupis philippinarum, Toxins 7 (2015) 2096-2120.

[32] H.-M. Chen, Y.-H. Lee, Y.-J. Wang, ROS-triggered signaling pathways involved in the cytotoxicity and tumor promotion effects of pentachlorophenol and tetrachlorohydroquinone, Chem. Res. Toxicol. 28 (2015) 339-350.

[33] H.-M. Chen, B.-Z. Zhu, R.-J. Chen, B. Wang Jr., Y.-J. Wang, The pentachlorophenol metabolite tetrachlorohydroquinone induces massive ROS and prolonged p-ERK expression in splenocytes, leading to inhibition of apoptosis and necrotic cell death, PLoS One 9 (2014).

[34] C. Pietsch, J. Hollender, F. Dorusch, P. Burkhardt-Holm, Cytotoxic effects of pentachlorophenol (PCP) and its metabolite tetrachlorohydroquinone (TCHQ) on liver cells are modulated by antioxidants, Cell Biol. Toxicol. 30 (2014) $233-252$.

[35] G. Atli, E.G. Canli, A. Eroglu, M. Canli, Characterization of antioxidant system parameters in four freshwater fish species, Ecotoxicol. Environ. Saf. 126 (2016) 30-37.

[36] H. Park, I.-Y. Ahn, J.K. Lee, S.C. Shin, J. Lee, E.-J. Choy, Molecular cloning, characterization, and the response of manganese superoxide dismutase from the Antarctic bivalve Laternula elliptica to PCB exposure, Fish Shellfish Immunol. 27 (2009) 522-528.

[37] C.D. Putnam, A.S. Arvai, Y. Bourne, J.A. Tainer, Active and inhibited human catalase structures: ligand and NADPH binding and catalytic mechanism, J. Mol. Biol. 296 (2000) 295-309.

[38] Y.M. Zhang, D.J. Huang, Y.Q. Wang, J.H. Liu, R.L. Yu, J. Long, Heavy meta accumulation and tissue damage in goldfish Carassius auratus, Bull. Environ. Contam. Toxicol. 75 (2005) 1191-1199.

[39] N. Garceau, N. Pichaud, P. Couture, Inhibition of goldfish mitochondria metabolism by in vitro exposure to Cd, Cu and Ni, Aquat. Toxicol. 98 (2010) $107-112$.

[40] B. Allam, D. Raftos, Immune responses to infectious diseases in bivalves, J. Invertebr. Pathol. 131 (2015) 121-136.

[41] X. Lu, C. Wang, B. Liu, The role of Cu/Zn-SOD and Mn-SOD in the immune 
response to oxidative stress and pathogen challenge in the clam Meretrix meretrix, Fish. Shellfish Immunol. 42 (2015) 58-65.

[42] A.A. Soldatov, O.L. Gostyukhina, I.V. Golovina, Antioxidant enzyme complex of tissues of the bivalve Mytilus galloprovincialis Lam. under normal and oxidative-stress conditions: a review, Appl. Biochem. Microbiol. 43 (2007) 556-562.

[43] R.K. Pipe, J.A. Coles, F.M.M. Carissan, K. Ramanathan, Copper induced immunomodulation in the marine mussel, Mytilus edulis, Aquat. Toxicol. 46 (1999)
43-54.

[44] S. Rajalakshmi, A. Mohandas, Copper-induced changes in tissue enzyme activity in a freshwater mussel, Ecotoxicol. Environ. Saf. 62 (2005) 140-143.

[45] V. Chatziargyriou, S. Dailianis, The role of selenium-dependent glutathione peroxidase (Se-GPx) against oxidative and genotoxic effects of mercury in haemocytes of mussel Mytilus galloprovincialis (Lmk.), Toxicol. In Vitro 24 (2010) 1363-1372. 